\title{
Unilateral Blindness Following Acute Methanol Poisoning
}

\author{
Jenny J. Lu • Ejaaz A. Kalimullah • Sean M. Bryant
}

Published online: 2 April 2010

(C) American College of Medical Toxicology 2010

Keywords Methanol · Blindness · Optic neuropathy

A 47-year-old man with history of alcoholism presented to the emergency department with altered mentation and "blurry vision." He was tachypneic and minimally responsive to

The authors have no declarations of interest to report.

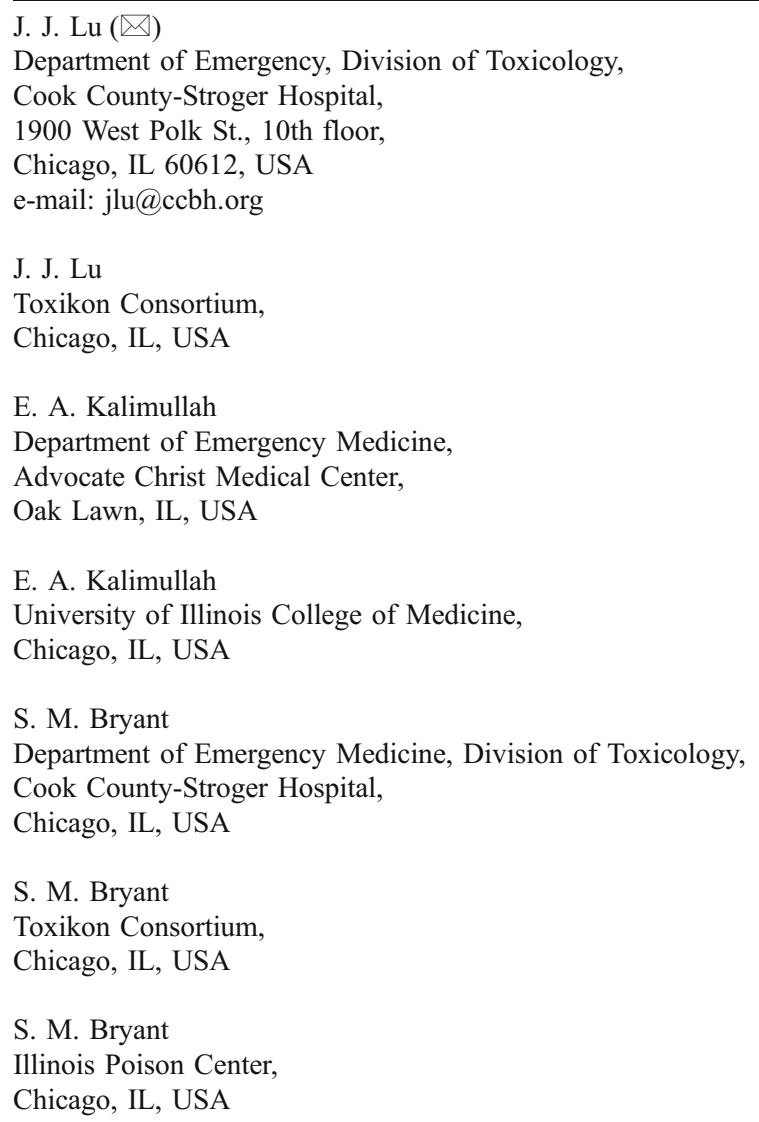

external stimuli, requiring endotracheal intubation. Vital signs were temperature $97.8^{\circ} \mathrm{F}$, blood pressure 216/139, pulse $140 / \mathrm{min}$, respiratory rate $26 / \mathrm{min}$, and $98 \%$ oxygen saturation on room air. The pre-intubation venous $\mathrm{pH}$ was 6.79 . Notable initial labs were sodium $135 \mathrm{mEq} / \mathrm{L}$, potassium $3.7 \mathrm{mEq} / \mathrm{L}$, chloride $95 \mathrm{mEq} / \mathrm{L}$, total $\mathrm{CO}_{2} 4 \mathrm{mEq} / \mathrm{L}$, blood urea nitrogen (BUN) $11 \mathrm{mg} / \mathrm{dL}$, creatinine $1.7 \mathrm{mg} / \mathrm{dL}$, anion gap 36, serum osmolality $361 \mathrm{mOsm} / \mathrm{kg}$, ethanol $<10 \mathrm{mg} / \mathrm{dL}$. An ethanol infusion, $\mathrm{NaHCO}_{3}$ drip, folic acid $1 \mathrm{mg}$, thiamine $50 \mathrm{mg}$, and pyridoxine $50 \mathrm{mg}$ were initiated. The patient was dialyzed for $6 \mathrm{~h}$ until resolution of the anion and osmolar gaps. The initial methanol level was $123 \mathrm{mg} / \mathrm{dL}$ with a postdialysis level of $17 \mathrm{mg} / \mathrm{dL}$. Ethylene glycol was undetectable. Following extubation, the patient, who had no prior ophthalmologic history and did not wear corrective lenses, was evaluated for persistent visual complaints. On exam, he had 20/20 acuity in the left eye, but only hand motion detection from the right eye. A right afferent pupillary defect and right optic disc pallor were also noted. Due to the unusual deficit, a magnetic resonance imaging (MRI) of the brain and orbits was obtained, revealing bilateral putaminal necrosis and edema at the retrobulbar and intracanalicular portions of only the right optic nerve (Fig. 1). MRI findings and cerebral spinal fluid (CSF) analysis did not provide alternative explanations for the ophthalmologic abnormalities. The patient was discharged on corticosteroids. On follow-up five months later, he had no visual improvement and remained ataxic and dysarthric.

\section{Discussion}

Acute methanol poisoning characteristically causes metabolic acidosis as well as neurologic and ocular toxicity. The manifestations of ocular toxicity may vary, but commonly 


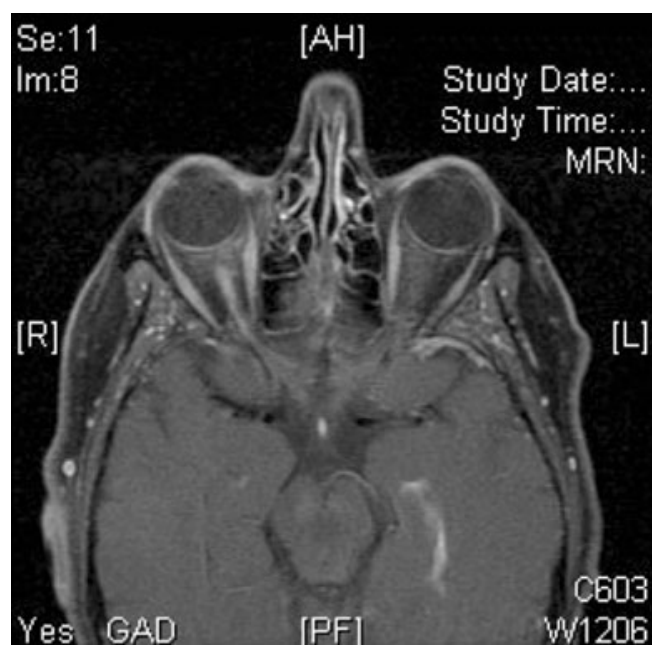

Fig. 1 MRI (T1 weighted) of the brain and orbits revealing enhancement of right optic nerve

include visual disturbances ranging from blurry or cloudy vision to total vision loss. Alterations in light, color, and depth perception may also occur $[1,2]$. Retinal and optic nerve damage is believed to be due to the accumulation of the formic acid metabolite and to the effects of edematous and ischemic insults on these structures. The extent and permanence of ocular complications are likely affected by the severity of poisoning as well as the duration of exposure to formic acid $[3,4]$. As with most, if not all, metabolic and toxicologic disorders, neurologic deficits are generally global or diffuse in nature while unilateral findings are unusual. Our patient displayed neurologic and radiographic findings consistent with methanol-induced basal ganglia injury. However, while asymmetric visual evoked potentials and optic nerve injury patterns following methanol poisoning have been reported [5], blindness in one eye with normal visual acuity in the other eye is rare. It is possible that a structural anatomic variation could provide one explanation for this discrepancy. We are aware of only one previous cursory mention of unilateral optic neuropathy from methanol poisoning [6] and present here, in more detail, this uncommon occurrence.

\section{References}

1. Benton C, Calhoun E (1953) The ocular effects of methyl alcohol poisoning: report of a catastrophe involving 320 persons. Am J Ophthalmol 36(12):1677-1685

2. Ingemansson SO (1984) Clinical observations on ten cases of methanol poisoning with particular reference to ocular manifestations. Acta Ophthalmol (Copenh) 62(1):15-24

3. Brent J (2009) Fomepizole for ethylene glycol and methanol poisoning. N Engl J Med 360(21):2216-2223

4. Yang CS, Tsai WJ, Lirng JF (2005) Ocular manifestations and MRI findings in a case of methanol poisoning. Eye 19(7):806-809

5. Hantson P, de Tourtchaninoff M, Simoens G, Mahieu P, Boschi A, Beguin C, Guerit JM (1999) Evoked potentials investigation of visual dysfunction after methanol poisoning. Crit Care Med 27 (12):2707-2715

6. Brahmi N, Blel Y, Abidi N, Kouraichi N, Thabet H, Hedhili A, Amamou M (2007) Methanol poisoning in Tunisia: report of 16 cases. Clin Toxicol (Phila) 45(6):717-720 